\title{
JOURNAL WRITING: EXERCISES IN CREATIVE THOUGHT AND EXPRESSION
}

\author{
Barbara Allen \\ Indiana University \\ Cathy A. Enz \\ Indiana University
}

\begin{abstract}
Claims that today's college students are less able writers than their predecessors in some "Golden Age" of university instruction are legion in the discourses of college educators. Asking students to keep a journal using one or a combination of the journal writing techniques suggested here is one method that can be used to enhance communication skills, logical analysis, and creative expression. Journal assignments may be designed so that their positive effects can be seen in improved analysis of problems and writing on essay exams, term papers, and case analyses. Perhaps the most important change that journals can facilitate, however, is an improved attitude toward writing itself.

In this paper we will focus on three uses of journal writing: to encourage creative expression, to strengthen logical thinking, and to help students improve specific writing skills. Numerous journal techniques are provided to accomplish these three purposes. Finally, we will discuss the process of making and evaluating these assignments.
\end{abstract}

\section{Why Use Journals}

The authors have tested the various exercises presented in this article over nine semesters of classroom use. At the end of each set of journal assignments, students are asked to evaluate their experience using journals for the purposes intended by the instructor. The comments of these students suggest that the journal assignments presented here can: (1) improve the confidence of the students as communicators, (2) help the students clarify goals, (3) help the students understand the application of course content to situations in their own lives, (4) help students become more creative problem solvers, (5) motivate students to seek further help with particular technical writing problems, and (6) improve performance on graded assignments which use writing as the medium for the expression of what the students have learned.

Journal writing exercises can be designed to focus on communication and creative expression rather than grading and competition. The student, rather than the teacher, has the opportunity to be the first judge of her or his own entries. By reading the journal the students 
can learn to evaluate the clarity and coherence of their own writing. In this way the person who had the experience evaluates whether what has been written communicates what she or he needs to remember or understand. Having a clear record allows the student to explore and develop skills for communicating that record to another. Hence, journals can allow students the opportunity to develop communication skills and approaches to problem solving in a nonevaluative, non-competitive, creative fashion.

A second instructional goal that journal writing accomplishes is to teach students a method of learning theories of organizational behavior (OB) through conscious analysis of their own experiences. At the foundation of what we teach students in $\mathrm{OB}$ are theories and ideas about how individuals may be expected to act given various contingencies. Students exist and behave in relation to others in a variety of organizational settings. Regardless of the particular theory of behavior an instructor would like to have students consider, the students' own lives are a laboratory for observing these theories in action. Journal writing exercises may be designed to help students: (1) learn to keep records (collect data), (2) look for patterns, (3) analyze cause and effect, (4) compare competing hypotheses regarding what "works" and does not "work" in circumstances they can specify, (5) synthesize the ideas of a theory with events they observe, and (6) apply theoretical ideas in new situations. Through the application of an OB perspective to a personal experience in their journals, students can learn the value of theoretical abstraction as a means to understanding specific events. Learning the usefulness of theoretical analysis through personal experience and application can pave a smoother road for the instructor faced with the task of making abstraction "meaningful."

Integrating journal assignments with other writing assignments can help the instructor look at students' writing, their understanding of key ideas, and their use of theories early in the course. Focusing on the goal of improving specific writing skills, the instructor may make suggestions to correct errors and improve the presentation of ideas before the students tackle the major course assignments which determine their grades. The opportunity to correct errors before they are made in graded assignments can be a great boon for students. The authors have been successful in using these assignments with four students for whom English was not their native language and two students who had diagnosed reading disabilities. These students in particular were aided by the opportunity to develop their analytical skills and written presentation of their analysis in the context of practice and practical application which these journal assignments provide. Instructors also obtain the benefits of helping their students improve instead of merely being critical arbitrators of their achievements through the administration of grades.

A multitude of journal writing assignments may be designed and integrated with a course on $\mathrm{OB}$. Table 1 lists and briefly describes ten journal exercises and activities an instructor can use in the classroom to help students explore the three instructional goals considered here. These exercises are designed to help students become more conscious of the sources of problems, ideas for class projects, creative solutions and, in general, new ways of seeing and 


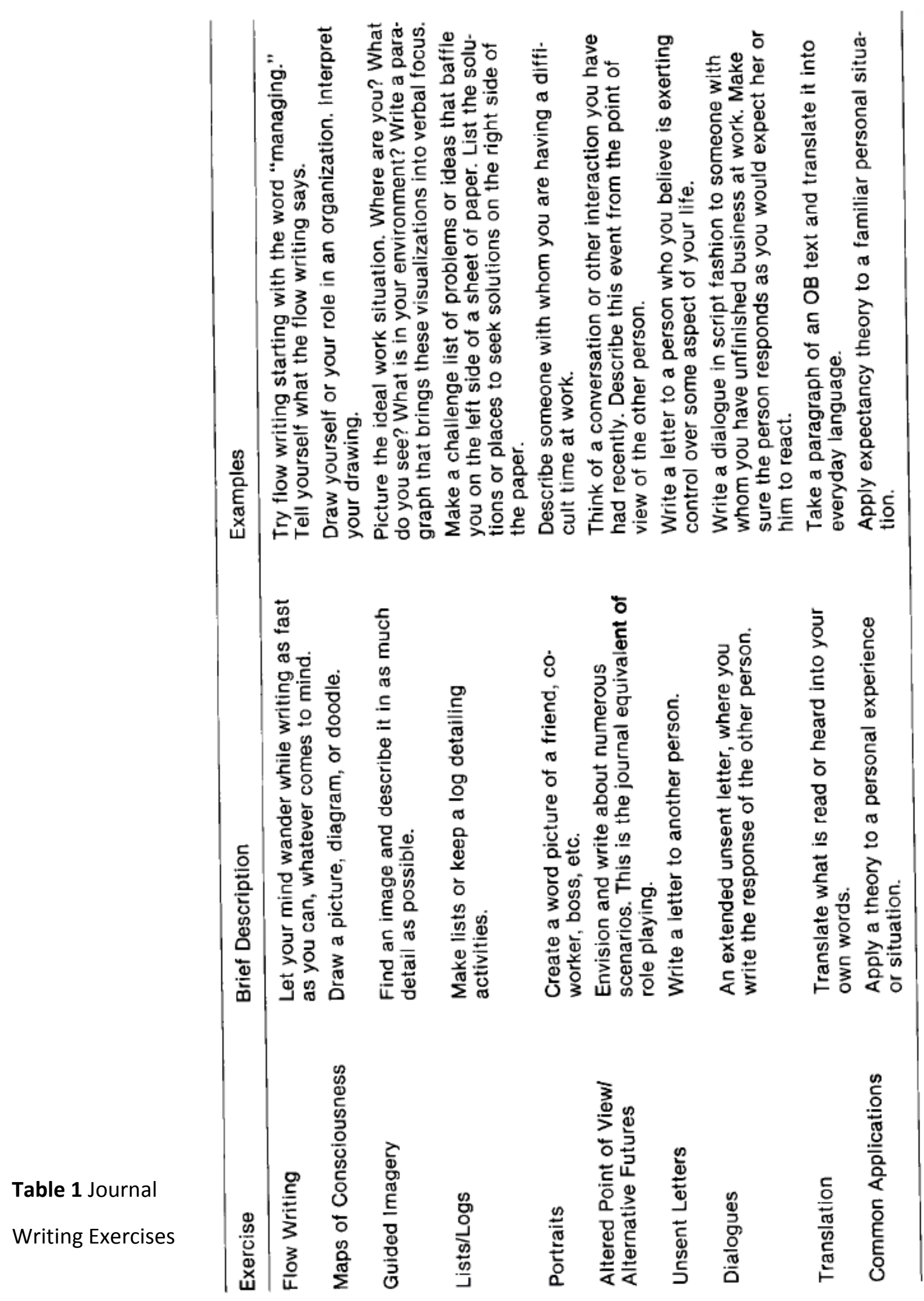


and thinking about the organizational environment of which they are a part. Greater detail is provided in Appendix A. Four examples of assignments which may be used to approach the instructional goals of logical thought, creative expression, and improved writing are discussed at length.

\section{Examples of Journal Exercises}

The journal writing exercises we have chosen to exemplify these three objectives of OB instruction may be integrated into a course in several ways, ranging from one-time, in-class exercises to longer units which integrate writing with other communication skills. Each exercise may also tap a range of self-exploration experiences, from the superficial to deep introspection. All levels of experience and amounts of integration are of value and the instructor may simply wish to consider which types of journal writing exercises are most appropriate to her or his instructional goals.

The first example, "Logs and Lists," may, for instance, be undertaken only to keep a record of thoughts, beliefs, goals or activities. Although such records may be seen from one vantage point as at the surface of communication, such an activity may be the essential foundation of any deeper analysis the student wishes to undertake. Moreover, record keeping is an activity with virtue of its own-as a permanent record of a series of activities or thoughts.

\section{Logs and Lists}

For many students, making a list is the most tangible way to get started bringing their criteria for judgment, decision-making processes, problem-solving methods, goals, values, or ideals to a more conscious level of knowing. There are many variations of list-making activities. Students may be asked to keep a log detailing their activities related to a class project. This log may be a simple list or an annotated account of activities and analysis of results which they believe are the positive or negative consequences of specific actions-what works and what does not. The instructor can use such logs to initiate student analysis of processes they use in making decisions or sequential activities they observe in case analysis. In order to help students become open to the creative ideas they have stored at sub-levels of consciousness, logs may also be kept of dreams or daydreams. An example of an assignment which shows how this type of journal writing could be incorporated into an OB course is the process log.

The process log is a detailed weekly record of what the student thinks and experiences while working on an action research-based paper. Such a process log affords students the opportunity to look back on the difficulties accompanying the project, thereby enabling them, at the end of the term, to recognize their early mistakes and learn what has occurred in the process of their research activitity.

Another variation on exercises which call for log and list making is a program for setting and achieving goals (see Appendix A). Students in OB courses are frequently asked to consider the motivation of actors within an organizational setting in terms of implicit and explicit goals: 
"organizational goals," "the goals of management," or "the goals of Jane, the division head." Yet often the students have had little, if any, experience with goal-motivated behavior-that is, thinking in terms of the steps they perceive as related to the achievement of a particular end. Thus, exercises in goal setting may be undertaken for the dual purposes of helping students analyze organizational goal setting and experience what is involved in the setting of goals. Such exercises may have the salutary side effect of improving the student's understanding of her or his goals in college, although this may not be the instructor's primary purpose.

In order to avoid discouragingly long or tedious lists, the instructor should take care to be specific about both the length of time students might be expected to spend on these exercises and the number of items they put in their lists at a minimum. For example, the directions in the assignment could suggest that they spend a minimum of ten minutes per day at least three days each week on these activities. Greater focus for these types of exercises increases the probability that the students can adapt the essence of the exercise to their specific situations. This adaptation of the exercise by the students may be necessary for them to see that they are the beneficiaries of the time spent in goal setting and keeping a journal. The instructions should further emphasize that the students deserve to take ten minutes from their days to think constructively about goals they would like to accomplish. The assignment encourages students' appreciation of each of the subgoal steps, including the beginning, by asking them to write about the accomplishments of the moment, as well as those projected in their schedule.

During the latter weeks of a goal setting program, the instructor may wish to include flow writing or other exercises to augment a goal setting program (see Appendix A). These additional exercises may help students understand more about the obstacles they place in the path of their achievement of a goal. Recognizing some of the ways they create struggles for themselves may be helpful when the instructor asks them to use these insights to understand the behavior of individuals in $\mathrm{OB}$ case studies. Other methods for helping students use insights from their own experiences to understand better a phenomenon in OB are "Translation" and "Common Application" exercises.

\section{$\underline{\text { Translation and Common Application }}$}

Translation and Common Application exercises can be designed so that the instructor can see if technical, theoretical, or abstract material is understood. These activities can also be used to clarify the need for precise technical or specialized language, as well as to improve the student's synthesis of ideas or information and ability to apply ideas or information in varying situations. Translations are especially useful as short assignments that help the instructor observe whether the student understands specific materials. These journal activities allow for regular and relatively unobtrusive corrections of the student's writing.

The assignment for a translation can be very simple: "Take paragraph 3 on page 25, and translate this paragraph into your own language." In essence, the student is being told that 
paragraph 3, page 25, is in a special language (which should usually be true of abstract, theoretical, or technical works); words which have particular meaning in our common parlance may have a special meaning for the student to discover in this paragraph. For example, the student may encounter words like "equality" in a paragraph about affirmative action or comparable worth. Numerous conditions may be judged as states of equality, depending on whether an author means "equal opportunity," "equal outcome," "equal social status," "equal pay," "equal hours of work," or "equal value" (according to various criteria). The student's understanding of specific technical definitions of "equality" as opposed to a colloquial slogan will be critical to her or his understanding of "equal" pay for "equal" work.

A simple translation exercise can deepen the student's awareness of the existence of technical language and increase the student's ability to critique the logic and coherence of her or his own writing and the writing of others. Through the critique of an author's use of language as a tool of theory, students gain insights into their own use of language. The ability to measure precision in their own analysis and communication of this analysis begins with the awareness of language that a translation exercise can facilitate.

Common Application exercises can take the student a step farther than translations by making possible the synthesis and application of ideas from a theoretical exposition or case study to a new situation. The Common Application exercise may ask the students to take an idea such as "the free rider problem" and show how this idea explains some of the behavior in their own experiences. The following is an excerpt from a student's account of a problem in her living situation, to which she applied Garret Hardin's analysis of the "tragedy of the commons" (in which "free riders" and "hold outs" create a dilemma for those who use a common resource):

I live with three roommates in a house in which we share a kitchen and kitchen utensils, plates, silverware, etc. Our "tragedy of the commons" is the mound of dirty dishes in the sink. Since the kitchen and all the utensils are "common property," free for anyone's use, and the kitchen sink is a common repository for dirty dishes, we have the problem that each roommate uses one or two utensils and thinks, "I'll clean this later." As in Hardin's commons, each person thinks her one item won't have that much effect, but of course the sum effect is devastating. As the dishes pile up, the situation changes a little. While at first each person was acting in a self-interested way without much intention to be inconsiderate, now it is necessary to be inconsiderate. Now each person has a strategy to "hold out" and wait to see if another roommate, one with a lower dirt threshold, will do all the dishes (provide a common good), so that she can "ride free" and get the benefit of a clean kitchen without any work. The problem is caused because we have no rules to make us change our behavior and Hardin suggests that we'd have to divide up the commons or give property rights to the sink and dishes. But I don't think that would work. We'd have no way to enforce the rules, we're all friends and we couldn't punish each other, that's just not in our understanding of how we should be 
with one another. (That's one of the problems I see with Hardin's solution being applied in a different context or culture than what he thinks is normal.) We might be able to come up with some rewards, though, and I'm going to suggest that we talk about that. This exercise has been useful, because now I can think of a way to bring this up without blaming anyone. It's the situation and now I see we're acting like the theory says we probably would, given this situation.

Not only do Translation and Common Applications allow the instructor to see what form the assigned readings of the course are taking in the minds of the students, but they also present an opportunity for making short writing assignments which may be evaluated and discussed for the purpose of improving the writing so that the solutions to problems become clearer. The journal entry quoted above provided the opportunity for the instructor to suggest some syntactical improvements so that the roommates could read and understand better the problem of concern to the student. The student may be motivated to improve the logical construction of an argument and various elements of writing skills (grammar, style, tone) if he or she recognizes the benefit of improved communication skills in a personal context.

Although there may be correct and erroneous translations of words and phrases and better or worse translations of paragraphs, the students may be corrected as if learning a foreign language. Subtleties of context, connotation, denotation, and idiomatic expression may be pointed out by the instructor through a series of translations. Students are not expected to know every turn of phrase on their first outings as translators. The instructor may use opportunities of errors to make the subtle point that there are degrees of precision in writing and that, as a human artifact, the tool of language never perfectly conveys the consciousness of one to another.

For the evaluation of journals to be effective, the instructor must engage a critique of logic and the elements of written communication at a level of understanding beyond the circling of misspelled words. This critical faculty may be taught to students through a succession of criteria for evaluation against which a series of journal entries may be weighed. These criteria may themselves be evaluated and improved as the exercises are developed.

Such improvements in the use of language and logic in discourse may be undertaken as graded or ungraded assignments, but they should be constructed and evaluated in ways which differ from the usual approach taken in essay exams, case studies, and term papers. First, the opportunity to repeat the assignment and make improvements is important in helping students internalize criteria for evaluating both logical thought and written communication skills. Second, in the case of translation, passages must be chosen which exemplify a few key elements of reasoning and communication on which the instructor is prepared to focus. The instructor must be able to evaluate the paragraph's suitability in terms of a particular educational objective, such as demonstrating theoretical biases, underlying assumptions, methods of argumentation, clarity of expression, or tone. For example, an instructor might teach students to assess the methods of argumentation by introducing the idea of syllogisms 
and then asking students to translate a paragraph chosen because it has the structure of a syllogism. The ability of the students to recognize and translate correctly the syllogism in question should be the basis of the instructor's evaluation.

Several other attributes of journal assignments recommend their use to enhance the effectiveness of other methods of instruction, testing, and evaluation. Journal assignments are flexible and can provide a basis for diagnosing specific writing problems and problems in the logical presentation of ideas, as well as for evaluating overall performance. Breaking down course content into short segments evaluated through appropriate journal assignments that build sequentially upon one another allows the instructor to pace material for individuals within the same class.

Journal assignments can also be constructed to encourage innovative approaches to problem solving, creative expression, and to motivate deeper consideration of abstract ideas by clarifying the relevance of course content to the students' personal situations. When the instructor is clear about the journals' purpose, she or he may construct an agenda of journal assignments consonant with the overall educational objectives of the course.

\section{Making Assignments}

The first question an instructor might consider in assigning journal exercises is whether to make the activity an in-class or take-home assignment. Several types of journal writing exercises listed in Table 1 are excellent in-class assignments for the release of creative ideas and discussion. Flow Writing can be used as a written analogue to "brainstorming," allowing students to explore the meaning of terms such as performance, authority, and motivation that they may encounter in the OB course. Similarly, Maps of Consciousness, Portraits, and Guided Imagery are appropriate for either in-class or take-home writing experiences. Exercises such as Portraits (in which the student "paints" a word picture of a person so that the latter could be recognized by someone who does not know her or him) can be used to explore the actors in a case study and help students see what kind of traits, characteristics, or behavior catch their attention.

One journal activity can also be used for more than a single educational purpose. For example, the Dialogue (see Appendix A) can be adapted to exercises which encourage creative expression, strengthen logical thinking, or help students improve specific writing skills. Through Dialogue students can explore technical aspects of writing such as grammar, syntax, tone or style. Dialogues such as the sort defined by Progoff (1977) can also be used to explore attitudes, beliefs and emotions in relationships and situations. Plato and Hume are part of a long-standing tradition of using dialogues to expose the differing premises and logical construction of philosophical argument. Depending on the instructor's purpose in assigning such a journal activity as the Dialogue, the students' final product and the instructor's subsequent evaluation will vary. 
Using several exercises in tandem can generate class discussion or can be the subject of a take-home assignment with an in-depth case analysis. Altered Points of View and Alternative Futures are exercises which can also be used in conjunction with other assignments. Alternative Futures help students learn to evaluate risks and make contingency plans and are thus appropriate for use with goal setting programs and case analysis. Altered Points of View represent the journal equivalent of role playing and can be used effectively in Common Application analysis.

These latter two types of exercises, Alternative Futures and Altered Points of View, usually lend themselves best to take-home writing assignments. Similarly, results are more satisfactory if Goal Writing Programs, Logs, Unsent Letters, and Dialogues are given the time and contemplation often unavailable in the classroom. If the instructor is certain about the purpose of the assignment (to stimulate discussion, to stimulate deep analysis, to stimulate introspection, to stimulate spontaneous creation), it is obvious which writing situation would be more appropriate. The best rule of thumb might be for the instructor to try the exercise in order to determine what length of time and writing situation are most likely to result in completed assignments which meet her or his expectations. If it is believed that a particular exercise is likely to be a catalyst for emotional responses (goal writing, unsent letters, and dialogues are potential vehicles for deeply personal ideas and feelings), it is unlikely that any inclass environment would be preferable to a take-home assignment.

The potential for students to respond emotionally to journal writing assignments is a topic about which the instructor might wish to think. Often teachers are wary of using these types of assignments because of the reactions that may accompany them. Caution is important in the introduction of any teaching methods that ask students to explore human relationships, and journal writing is no exception. If students find they are identifying emotional problems through their journals, professional counseling should be suggested. It is unwise for the OB instructor to become involved in these issues if they are beyond the range of her or his expertise.

\section{Evaluating Journal Writing}

Whether and how to evaluate journal writing assignments is another issue the instructor must consider. Numerous assignments could be optional or for extra credit. If it is essential to ensure that students try these assignments, however, making the entire program of assignments count for a small percentage of their total grade may be necessary. For example, a process log could be worth ten percent of the final grade, five goal setting exercises could equal ten percent of the final grade, or one Altered Points of View analysis could substitute for a case analysis in the final grade. This type of grading scheme does not make the journal an entirely optional assignment, but those who are averse to completing the assignment for personal reasons are not significantly penalized. The instructor might further alleviate the tension of grading by accepting the assignments on a pass/fail basis. If the student hands in an attempt, she or he receives a point or a check; failure to turn in an assignment results in a zero. 
Dialogues, Unsent Letters, Flow Writing, Guided Imagery, Maps of Consciousness, and Goal Setting seem to obtain best results when grading is minimal or absent.

Alternatively, some journal writing activities lend themselves to greater integration with the overall grading scheme. Translations and Common Analysis exercises can be given letter or percentage rankings and can be treated as major assignments for which final grades are given. Altered Points of View and Alternative Future analyses can be graded along with case analyses. Process Logs can be made the major writing assignment of the class, depending on how detailed you wish the students' analyses of their activities to be. Each of these journal writing activities can also be designed in a framework which de-emphasizes the grading of writing and promotes creative analysis. Allowing the students to correct assignments and turn them in for evaluation more than once offers a compromise between the desire to treat the assignment seriously by giving it a role in the final grade and the desire to encourage creative ideas in an environment in which improvement over time is a priority.

It is also useful to give students an opportunity to evaluate their experiences with these assignments. When using more than one technique to approach a journal assignment or more than one method of log keeping, goal setting, or translating, having the students compare these techniques or methods helps the instructor decide what is appropriate for different conditions, how to give clear instructions, and, in general, how to improve the assignments. In addition, the students can analyze what types of journal writing work best for them. The major caveats which come from the students' evaluation of these assignments are: (1) journal activities must be integrated with the overall goals and assignments of the course; (2) the instructor must have a clear purpose in designing the assignments, as well as a clear method of evaluating the students' work; and, (3) the students must have a clear understanding of the journals' purpose.

Experimenting with different approaches to incorporating journal writing into an $\mathrm{OB}$ course is perhaps the best advice. Being clear about the purpose and role the journal is to play is the first order of business. Trying the exercises before assigning them in order to get some idea of what the students are expected to do will further refine assignments and hone expectations. Realizing that even a simple, in-class journal writing assignment can yield immediate improvements in creative analysis and the desire to write is sufficient motivation to give journal writing a whirl.

\section{References}

Baldwin, C. (1977). One-to-one: Self-understanding through journal writing. New York: M. Evans \& Co.

Barreno, M.J., Horta, M.T., \& de Costa, M.V. (1973). The three Marias: New Portuguese letters. New York: Doubleday.

Clay, M., \& Badami, M.K. (1984). Discovering our own voice: The whys and hows of journal writing. Workshop, Bloomsburg University. 
de Bono, E. (1967). New think. New York: Basic Books.

Hume, D. (1970). Dialogues concerning natural religion. Indianapolis: Bobbs-Merrill.

James, A. (1964). The diary of Alice James. New York: Dodd, Mead.

Laut, P. (1978). Money is my friend. Hollywood: Trinity Publications.

Lifshin, L. (1982). Ariadne's thread. New York: Harper \& Row.

Mallon, T. (1984). A book of one's own: People and their diaries. New York: Ticknor and Fields.

McKim, R. (1972). Experiences in visual thinking. Belmont, CA: Brooks/Cole.

Mills, C.W. (1959). The sociological imagination. (Appendix on intellectual craftsmanship). New York: Oxford University Press.

Plato. (1937). The dialogues of Plato. New York: Random House.

Progoff, I. (1977). At a journal workshop: The basic text and guide for using the intensive journal process. New York: Dialogue House, p. 11.

Rainer, T. (1978). The new diary. Los Angeles: J.P. Tarcher, Inc.

Ray, S. (1983). Celebration of breath. Berkeley: Celestial Arts.

Ray, S. (1981). The only diet there is. Berkeley: Celestial Arts.

Reinharz, S. (1979). On becoming a social scientist. San Francisco: Jossey-Bass.

Sand, G. (1929). The intimate journal of George Sand. London: Williams \& Norgate. Whyte, W.F. (1943). Street corner society. (Appendix on method). Chicago: University of Chicago Press.

Woolf, V. (1954). A writer's diary. New York: Harcourt Brace Jovanovich.

\section{Appendix A}

\section{Techniques for the Use of Journal Writing}

To start the process of writing - RELAX. Don't worry about spelling, writing in complete sentences, or even making sense. Just write for the fun of it. In this appendix, techniques for journal writing will be detailed to help the instructor incorporate journals into the classroom.

\section{Flow Writing}

This exercise taps what Christian Baldwin (1977) calls a "hand-to-mind" process.

Students can use this exercise to see what they have to say to themselves. You can suggest they start with a word, an image, a sentence, or an observation, and let their minds wander while 
writing as fast as they can whatever comes to mind (Clay \& Badami, 1984). After writing for several minutes, ask your students to take a separate sheet of paper and write a paragraph describing and analyzing what they wrote in the flow-writing activity.

Students can practice variations on this exercise, using such terms, images, or questions as authority, performance, corporation, entrepreneur, profit, success, motivation, politics, niche, acquiring, and corporate culture.

\section{Maps of Consciousness}

This exercise incorporates some of the ideas about visual thinking pioneered by Edward de Bono (1967) and Robert McKim (1972). Many students find that drawing pictures or diagrams allows them to express their ideas, goals, or solutions in a way that more clearly tells them what's on their minds. These experiments work particularly well for those students for whom writing is an obstacle rather than a channel for creative ideas. The basic assignment for a map of consciousness can range from the analysis of unstructured doodling, to instructions to draw verbs such as "leap" or "explode," to highly structured tasks such as "draw yourself, your role, or your niche in the organization and write a paragraph interpreting your drawing."

\section{Guided Imagery}

Guided imagery experiences can be the capstone for exercises which coordinate creative visualization and verbalization. The basic exercise asks the participant to find an image and describe it for herself or himself in as much detail as possible. The image could be "the ideal job," "a great business venture," "an ideal coworker," "the ideal professor," "radiant wellbeing," "myself at 75," a goal such as "winning the Boston Marathon" or "graduating from college," or whatever is appropriate. Help your students see the relationship between clearly visualizing and concretely verbalizing their goals or desired ideals. You can structure this exercise so that it acts as a catalyst to identify processes or procedures for attaining goals or solving problems by clarifying students' ideas about what is and what could be.

\section{$\underline{\text { Lists/Logs }}$}

Students may be asked to keep a log detailing their activities related to a class project. This log may be a simple list or an annotated account of activities and analysis of results which they believe are the positive or negative consequences of specific actions-what works and what doesn't. You can use such logs to initiate student analysis of processes they use in making decisions or sequential activities they observe in case analysis.

A simple goal-setting list might be used over a five-week period in a course. During week one, ask students to spend at least ten minutes a day writing a "Master List of Goals." Each entry should be dated. During the second week have your students break their "Master Lists" down into categorical lists. The selection of categories should be left up to the individual and should be related to her/his life, but you might help students get started by suggesting rudimentary headings. In week three, have students reclassify the goals within each category 
according to whether the particular goals are tangible or intangible. Then ask them to prioritize the tangible and intangible subcategories, taking care to record the criteria used to determine their priorities. During the fourth week ask students to evaluate their strengths and weaknesses relative to the attainment of the top one or two goals in each category and to the list of benefits they believe they would receive from obtaining these top-priority goals. In the final week, have students outline the steps involved in achieving one or two of their highest priority goals. As part of the outlining process they should list the obstacles they might encounter at each step and present at least one idea of how to avoid or surmount each obstacle. At this point you might encourage your students by asking them to list all the goals they have already achieved that are similar to these subgoals. As a last step, have students compare the list of benefits they expect to receive to their outline of steps/plan for obstacles and consider whether the goal in question is worth the effort or is still desirable.

\section{Portraits}

One way to work on specific kinds of challenges students meet in their relationships with people in a journal is to paint a "word-portrait" of a co-worker, fellow- student, friend, parent, professor, manager, boss, departmental chair, division head, business partner, foreman, employee, or spouse. Ask your students to describe that person to someone who doesn't know her or him. Clay \& Badami (1984) suggest that those who try this exercise are often surprised by what they choose to mention in their portraits: writing such a portrait often reveals as much about the writer as it does about the person presented in the portrait.

\section{Altered Point of View/Alternative Futures}

One device described by McKim (1972) which helps a student learn to evaluate risk and uncertainty, and become conscious of making decisions under these conditions, is to envision alternative futures. Think of a decision that would be likely to influence your future and write this decision in your journal. Next, write down 10 to 12 conditions which will influence the outcome of your decision (e.g., economic factors, other people who may be concerned). Think carefully about these conditions-this obviously is the point where limits to your information (uncertainty) can have a major influence on the consequences of your decision. Write three scenarios of the outcome of the decision as you vary the conditions.

Another device for helping students focus on alternatives to understand events or solve problems is the "altered point of view." You may make these exercises tap personal experiences of the students by focusing on their own relationships, or you may ask the students to write from the point of view of a fictional character (e.g., a person in a case study). Such exercises are the journal equivalent of role playing.

\section{$\underline{\text { Unsent Letters }}$}

The unsent letter described by Clay \& Badami (1984) further extends the idea of analyzing events and relationships considered in the exercises of altered points of view. The 
basic exercise entails writing a letter to someone whom the students believe exerts control over some aspect of their lives. The person may be dead or alive, because the point of the letter is the insight the students gain into their own response to that person, and not their messages to her or him. If this exercise is used in conjunction with other journal exercises, the students may have a much deeper understanding of the events, situations, problems, environment of the problem, structure of their interactions, and themselves after writing an unsent letter.

\section{Dialogues}

The dialogue, as developed by Progoff (1977) and Clay \& Badami (1984), is an extension of the unsent letter, with the recipient being allowed a response. The students may enter into dialogues with some aspect of their own personalities, persons they know, fictional figures, dream figures, their religious or cultural heritage, social groups, institutions, inanimate objects, or projects, to name a few "actors" who may take part in the dialogue.

Assemble a list of people at work with whom you have "unfinished dialogues." These dialogues may or may not have actually occurred, and they may be positive or negative in content and your feelings about them. The important criterion is that you feel these are people with whom you have some "unfinished business" or something you'd like to say to or hear from them. Select one of the people on your list and on a separate sheet of paper go through the following procedure: (1) write a short focusing statement about your current relationship with this person; (2) make a set of "stepping stones" (how you have come to this current point in your relationship) from your point of view and from her or his; (3) write a dialogue in script fashion as it comes to you, making sure to have the person respond to you as you would expect her or him to react to what you are saying.

\section{$\underline{\text { Translations }}$}

The first step in utilizing information is simply to know the information. Often when students encounter theories or even alternate points of view, they cannot understand the information because of their own language or experience. The translation of what a writer or speaker says into the student's own words in a journal entry can illuminate the basis of misunderstandings and the basis on which sympathetic understanding can be built. When a theory concerning some complex organization is being studied, the students can be asked to translate the key paragraphs into their own language in a journal entry.

\section{Common Applications}

A variation of translations involves applying theories to personal situations. Students can be asked to take a specific theory discussed in class or the textbook and apply the theory to a current situation or circumstance. In this way the student personalizes and gains greater understanding of an abstract idea or theory. 